\title{
The application of terrestrial laser scanner and SfM photogrammetry in measuring erosion and deposition processes in two opposite slopes in a humid badlands area (central Spanish Pyrenees)
}

\author{
E. Nadal-Romero ${ }^{1}$, J. Revuelto ${ }^{2}$, P. Errea ${ }^{2}$, and J. I. López-Moreno ${ }^{2}$ \\ ${ }^{1}$ Institute for Biodiversity and Ecosystem Dynamics, Earth Surface Science Research Group (IBED-ESS), \\ University of Amsterdam, Amsterdam, the Netherlands \\ ${ }^{2}$ Instituto Pirenaico de Ecología (CSIC), Procesos Geoambientales y Cambio Global, Zaragoza, Spain
}

Correspondence to: E. Nadal-Romero (m.e.nadalromero@uva.nl)

Received: 16 March 2015 - Published in SOIL Discuss.: 7 April 2015

Accepted: 31 July 2015 - Published: 19 August 2015

\begin{abstract}
Erosion and deposition processes in badland areas are usually estimated using traditional observations of topographic changes, measured by erosion pins or profile metres (invasive techniques). In recent times, remote-sensing techniques (non-invasive) have been routinely applied in geomorphology studies, especially in erosion studies. These techniques provide the opportunity to build high-resolution topographic models at centimetre accuracy. By comparing different 3-D point clouds of the same area, obtained at different time intervals, the variations in the terrain and temporal dynamics can be analysed. The aim of this study is to assess and compare the functioning of terrestrial laser scanner (TLS, RIEGL LPM-321) and structure-from-motion photogrammetry (SfM) techniques (Camera FUJIFILM, Finepix x100 and software PhotoScan by AgiSoft) to evaluate erosion and deposition processes in two opposite slopes in a humid badlands area in the central Spanish Pyrenees. Results showed that TLS data sets and SfM photogrammetry techniques provide new opportunities in geomorphological erosion studies. The data we recorded over 1 year demonstrated that north-facing slopes experienced more intense and faster changing geomorphological dynamics than south-facing slopes as well as the highest erosion rates. Different seasonal processes were observed, with the highest topographic differences observed during winter periods and the high-intensity rainfalls in summer. While TLS provided the highest accuracy models, SfM photogrammetry was still a faster methodology in the field and precise at short distances. Both techniques present advantages and disadvantages, and do not require direct contact with the soil and thus prevent the usual surface disturbance of traditional and invasive methods.
\end{abstract}

\section{Introduction}

\subsection{Humid badlands: strong geomorphological dynamics}

Previous studies defined badlands as areas with scarce or no vegetation, where human activities, especially agriculture, are not possible (e.g. Alexander, 1982; Bryan and Yair, 1982; Fairbridge, 1968; Howard, 1994). Although badlands are considered characteristics of arid and semiarid environ- ments, they are also found in humid and subhumid areas (Gallart et al., 2013). Badlands are a landscape with a very high frequency and magnitude of geomorphological processes, resulting in rapid landscape evolution, which makes them "ideal field laboratories". Sheet wash erosion, gullies and rills, landslides, and mudflows are often observed in badland areas; the constantly changing landscape makes it very difficult to analyse geomorphological dynamics and measure erosion. 


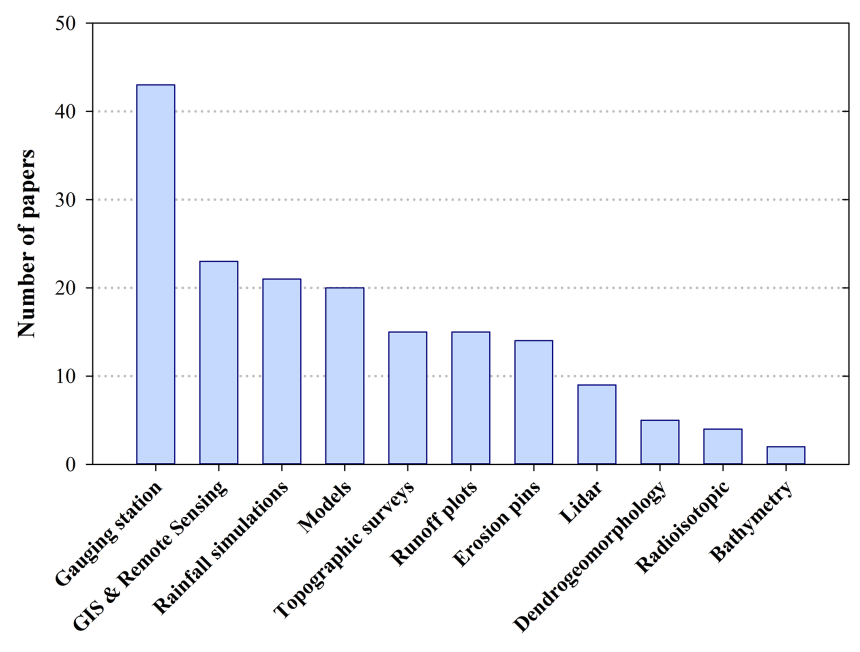

Figure 1. Distribution of soil erosion studies in badland areas according to different methodologies.

In general, badland areas show high erosion rates. The recorded values depend on the applied methodologies (Sirvent et al., 1997), on the spatial scale of measurement (NadalRomero et al., 2011, 2014) and also on the temporal scale, as erosion rates show high inter-annual variability (GarcíaRuiz et al., 2015). A recent comprehensive review by NadalRomero et al. (2011, 2014) of the scale dependency of sediment yields from badland areas in Mediterranean environments showed extensive variability in erosion rates and sediment yields. In the Tabernas badlands, Cantón et al. (2001) measured very low erosion rates $\left(0.08-0.35 \mathrm{~mm} \mathrm{yr}^{-1}\right)$ due to the low frequency of rainfall. Lam (1977) obtained $17.36 \mathrm{~mm} \mathrm{yr}^{-1}$ in the Hong Kong badlands. Higher values were registered in subhumid badland areas of southern Tuscany (15-20 $\mathrm{mm} \mathrm{yr}^{-1}$ ) (Cicacci et al., 2008) and the Prealp catchments in France, with erosion rates of over $30 \mathrm{~mm} \mathrm{yr}^{-1}$ (Chodzko et al., 1991). Recently, Vericat et al. (2014), using a non-invasive technology, a terrestrial laser scanner (TLS), measured an annual soil loss of around $60 \mathrm{~mm} \mathrm{yr}^{-1}$ in the eastern Pyrenees (Spain).

\subsection{Review: methodologies for analysing geomorphological processes and erosion rates in badlands}

The geomorphology of badlands has been extensively studied for the last 30 years and there is a substantial body of literature on the subject. In this context, numerous methods have been used to understand geomorphological dynamics (erosion and deposition processes) and quantify erosion rates. The following presents an overview of the main methodologies for investigating erosion rates and sediment yields in badlands.

A total of 171 papers (starting from 1956) were identified using the Scopus and the ISI Web of Knowledge databases

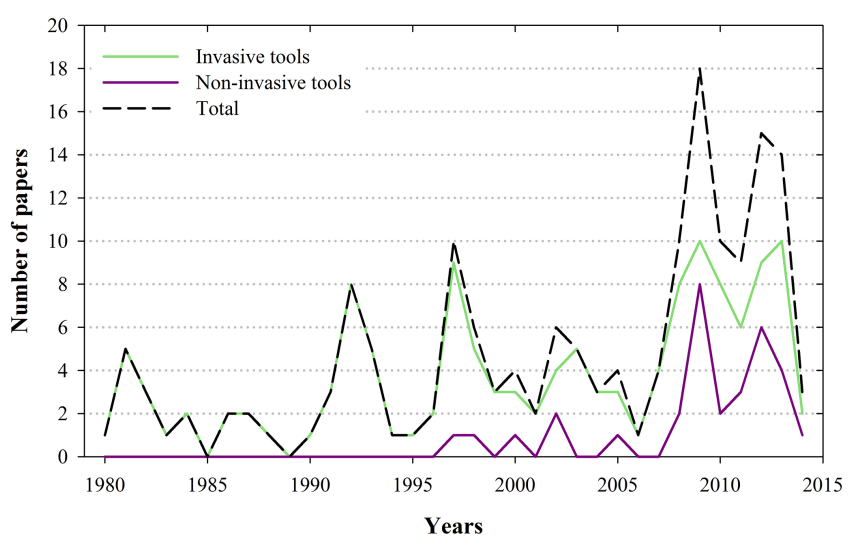

Figure 2. Evolution of different methodologies and difference between invasive and non-invasive methods.

(search terms: "Badlands and erosion rates" and "Badlands and Sediment Yield"). The obtained information enables the classification of the studies according to the different methods (Fig. 1).

The analysis showed that there is no standard protocol for measuring erosion and sediment yield in badland areas, with a variety of methods (at different temporal and spatial scales) being used, both conventional and new remotesensing techniques. The most commonly reported method is a gauging station (e.g. Nadal-Romero et al., 2008), seen by different authors as the best approach for measuring sediment transport (Walling, 1991). Remote-sensing technologies (e.g. Martínez-Casasnovas and Ramos, 2009), rainfall simulations (e.g. Martínez-Murillo et al., 2013) and erosion models (e.g. Mathys et al., 2003) were recorded in about 20 studies. Topographic surveys (e.g. Sirvent et al., 1997), runoff plots (e.g. Gallart et al., 2013) and erosion pins (e.g. Vergari et al., 2013) were used a bit less often (approximately 15 studies each). On the other hand, dendrogeomorphological techniques (e.g. Ballesteros-Canovas et al., 2013), TLS data acquisition (e.g. Sáez et al., 2011; Vericat et al., 2014), radioisotopic measurements (e.g. Sadiki et al., 2007) and bathymetric surveys (e.g. Grauso et al., 2008) have been sporadically applied in badland studies (Fig. 1).

The methods were classified as invasive tools (mostly traditional methods, e.g. gauging station, rainfall simulations, topographic surveys, runoff plots, erosion pins) and noninvasive tools (mostly new technologies, e.g. remote sensing, TLS, structure-from-motion photogrammetry, aerial pictures). The annual evolution of the different methods is represented in Fig. 2 (data from 1980, $n=164$ ). Figure 2 indicates that (i) during the last 30 years, studies on soil erosion in badlands have increased (see also Gallart et al., 2013); (ii) the few studies during the 1980 s all used traditional invasive tools; and (iii) from 1996, non-invasive methods are starting to be used in erosion studies in badland areas, with the sharpest increase in 2007. 


\subsection{New remote-sensing techniques: terrestrial laser scanner and SfM photogrammetry}

Field methods for geomorphological processes analysis and soil erosion quantification have evolved from traditional methods (most of them invasive) to those that do not disturb the soil (non-invasive). In the last decades, techniques to rapidly acquire high-density topographic data have proliferated; however, the tools to adequately analyse change within these complex data sets have only now become accessible (Barnhart and Crosby, 2013).

TLSs are a non-intrusive high-precision tool designed to retrieve information on the topographic characteristics of any surface. TLS use lidar technology (light detecting and ranging), to accurately measure the distance from the device to the desired surface. By measuring the distance at thousands of points, 3-D point clouds of a very high spatial resolution are obtained. This information makes it possible to generate digital elevation models (DEMs) that accurately reproduce the topographic surfaces. TLS serves as a monitoring tool to observe changes in surface morphology, and the data collected with a TLS can be used for both calculations of volumetric changes as well as documentation of surface conditions (development of rills, roughness etc.). The acquisition time is relatively short, and the precision is sufficient for detailed erosion studies in very active areas. The highresolution topographical data already obtained with TLS in badland areas (e.g. Lucía et al., 2011; López-Saez et al., 2011; Vericat et al., 2014; Castillo et al., 2015) encourage its application in other study sites.

Digital photogrammetry has generated an improvement in topographic methods, due to a better accessibility to a wider variety of users, its low cost, and also due to the increased automation of the photogrammetric routines (Fonstad et al., 2013). Recently, structure-from-motion (SfM) techniques, developed by the computer vision community, were adapted to generate high-resolution and quality digital terrain models. Classical (stereoscopic) photogrammetry is based on 3$\mathrm{D}$ reconstruction models by superimposing two images of the same area from different perspectives. SfM is based on the reconstruction of the 3-D geometry from the matching of multiples images generated from different points of view. Pictures can be taken at different scales and the position, orientation and distortion can be unknown. SfM differs from stereoscopic photogrammetry because it uses image matching algorithms to recover randomly acquired images and to detect points in common elements.

The biggest difference between both methods is the need to use ground control points (GCPs) for the 3-D model resolution. In classical photogrammetry, the collinearity is solved after the introduction of the GCPs; in SfM, collinearity is solved from the common elements of the images. So, if there are errors in the measurements of the GCPs, they are propagated to the final result (Fonstad et al., 2013). Through SfM, the final quality of the point cloud is based on a high num- ber of common points ( $>1000)$ that have been automatically generated.

The information from either aerial or terrestrial photographs is processed using one of a number of available software solutions, creating 3-D point clouds from several images of one area. Today, this tool offers new possibilities and innovative procedures, like creating DEMs in automatic mode to reconstruct surfaces (Bitelli et al., 2004). During the past 20 years, intensive research was published on the automation of the information extraction from digital images (e.g. the continuous development of processing algorithms) (Baltsavias, 1999). Several scientific fields, like geoarcheology and architecture, have already accepted photogrammetry as a useful tool (e.g. Cardenal Escarcena et al., 2011; Verhoeven et al., 2012; Martínez et al., 2015; Nadel et al., 2015) and its advantages for geomorphological research have been long recognized (Castillo et al., 2012). In the last 5 years various studies have taken advantage of the possibilities offered by geomorphology to generate terrain models using SfM photogrammetry (Gómez-Gutierrez et al., 2014; Kaiser et al., 2014; Michetti et al., 2015; Westoby et al., 2012).

The main objective of this research is to assess and compare TLS and SfM photogrammetry methods for the evaluation of geomorphological processes (erosion and deposition) and topographic changes in two opposite active slopes (north- and south-facing) in a humid badlands area in the central Spanish Pyrenees. Annual topographic changes will be evaluated and geomorphological processes will be spatially analysed.

\section{Materials and methods}

\subsection{Study area: the Araguás catchment}

The Araguás catchment $\left(0.45 \mathrm{~km}^{2}\right)$ is a north-south oriented tributary of the Lubierre River, located in the central Spanish Pyrenees. The altitude ranges from 780 to $1105 \mathrm{~m}$ and it has a substantially large badlands area spreading over $25 \%$ of the catchment (Fig. 3).

The climate of the area is sub-Mediterranean with Atlantic and continental influences (Creus, 1983). The average annual rainfall is about $800 \mathrm{~mm}$, varying from 500 to $1000 \mathrm{~mm}$ annually, and the average temperature is $10^{\circ} \mathrm{C}$.

Badlands occur on the Eocene marl of the Inner Pyrenean Depression (marls with interbedded decimetre-scale sandy layers). Nadal-Romero and Reguiés (2010) demonstrated that the main causes of regolith development and weathering processes are the alternating freeze-thaw and wetting-drying cycles (being maximum in winter and summer).

The Araguás catchment has been monitored since 2004 to study the hydrological and sedimentological dynamic in the badlands area, using a gauging station at the outlet of the catchment. Previous studies showed that the dynamics of weathering and erosion processes are the principal factors controlling geomorphological development, showing ex- 


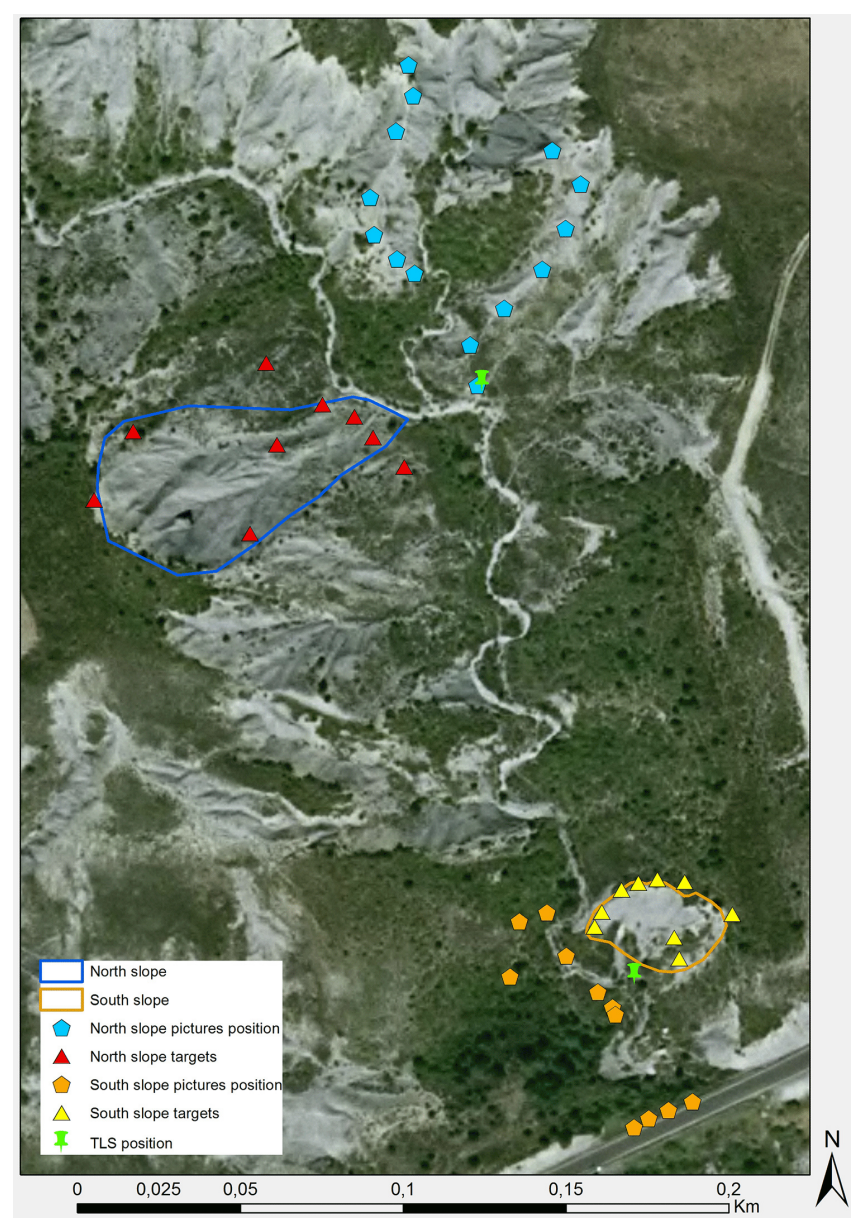

Figure 3. Field site location, Araguás catchment. Detailed image of both selected slopes.

treme hydrological and sedimentological responses (NadalRomero and Regüés, 2010). The badlands are very active: intense sheet wash erosion, gullying and rilling, with heavy mudflows during the most intense rainstorms produce substantial annual sediment yields (Nadal-Romero et al., 2008).

Two slopes with opposite aspect (facing north and south) were selected to apply the TLS and photogrammetric surveys (Fig. 3). These slopes were chosen based on two criteria: (1) according to the different geomorphological processes that can be observed on the dry slope (south-facing) and on the more humid one (north-facing), and (2) according to the differences in the surveyed areas and on the working distances for data acquisition with both methods (TLS and $\mathrm{SfM})$. The analysed extensions of the north and south slopes are 3200 and $560 \mathrm{~m}^{2}$, respectively. The average working distance for the TLS in the north-facing slope is $102 \mathrm{~m}$, while for the south-facing slope is $25 \mathrm{~m}$. The pictures for the SfM photogrammetry software were taken from an average distance of 100-150 m for the north-facing slope, and 40-60 m for the south-facing slope.

\subsection{Terrestrial laser scanner}

The device used in the present study is a long-range TLS (RIEGL LPM-321) (see Revuelto et al., 2014, for the technical characteristics of the TLS, the procedure used for scanning, and for the post-processing information).

Indirect registration (target-based registration) was used to merge the information from the different scan station and for transforming the local coordinates of the obtained point clouds into a global coordinate system. The point cloud transformation makes it possible to compare scans made on different survey days. The indirect registration considers fixed reflective targets placed at reference points (metallic stakes), which are placed at the same positions in the study site. We installed nine targets on the north-facing slope and nine targets on the south-facing slope (the high number of targets increases the robustness of the experimental setup; see Revuelto et al., 2014), each was a cylindrical reflector $0.10 \mathrm{~m}$ in diameter placed at a height of $0.10 \mathrm{~m}$. TLS automatically obtains 3-D point clouds but with a main limitation, we have to only work from a single position due to time restrictions.

Once the formal steps were completed (e.g. atmospheric correction, scan of targets, selection and delimitation of the area of interest), we started with the scan of the selected slopes.

In this study, on the north-facing slope the average resolution in point cloud acquisition was 625 points $\mathrm{m}^{-2}(0.04 \mathrm{~m}$ linear distance between points) and the angular scanning resolution was $0.027^{\circ}$. On the south-facing slope the resolution was 1890 points $\mathrm{m}^{-2}(0.023 \mathrm{~m})$ and the angular scanning resolution was $0.054^{\circ}$. For the areas closer to the TLS, the point resolution increased while at longer distances it decreased. This is one of the main limitations of the technology: it does not enable a consistent distribution of the acquired information.

Finally, when the scan was completed, photographs were taken using a digital camera coupled to the scanner to capture useful RGB (red-green-blue) information for each point.

\subsection{Structure-from-Motion photogrammetry}

Structure-from-motion photogrammetry allows for the creation of 3-D models from multiple overlapping images taken at distinct triangulation angles. In this case, we used the FUJIFILM Finepix $\times 100$ camera with a focal length of $23 \mathrm{~mm}$ (equivalent to a fixed lens of $35 \mathrm{~mm}$ ) and a resolution of $12 \mathrm{Mpx}(4288 \mathrm{px} \times 2848 \mathrm{px})$. In each survey, 17 pictures of the north-facing slope were taken at an approximate distance of $100-150 \mathrm{~m} ; 15$ pictures of the south-facing slope were taken at an approximate distance of $40-60 \mathrm{~m}$. The pictures were taken by hand following a set walking itinerary. The images were analysed with Agisoft Photoscan Professional Edition ${ }^{\circledR}$ software, generating a 3-D point cloud of the study area. Differences in lighting can cause problems during data processing and Agisoft software is a helpful tool to over- 
come this risk, as it estimates the potential error and deletes questionable pictures. The spatial resolution of the generated point clouds depends on the quality of the model processed with the images obtained with the camera. In this study, we used higher-resolution modes, which provided a spatial resolution of 970 points $\mathrm{m}^{-2}$ for the north-facing slope, and 2800 points $\mathrm{m}^{-2}$ for the south-facing slope. A high resolution of the original images would offer better texture and a higher resolution would allow finding key points in the photo set. Similarly, decreasing the distance between the camera and the feature of interest is related to increasing the spatial resolution of the photograph and would enhance the spatial density and resolution of the final point cloud (Westoby et al., 2012).

\subsection{Data processing}

In order to georeference both data sets (SfM photogrammetry and TLS point clouds) into the same coordinate system, we applied indirect registration (target-based) using the reference point coordinates of the targets (coordinates acquired with the TLS). Based on the target coordinates, a transformation matrix to a common coordinate system (which is named project coordinate system) using RiPROFILE 1.6.2 software is generated for the TLS point cloud. The standard deviation was lower than $0.015 \mathrm{~m}$ in all the TLS scans, which is in accordance to errors reported in other studies (Revuelto et al., 2014; Prokop, 2008). Similarly, the point cloud obtained from SfM photogrammetry is transformed onto the same coordinate system by a transformation matrix calculated in $\mathrm{Ag}$ isoft Photoscan using the TLS-recorded target coordinates with standard deviation below $0.025 \mathrm{~m}$. The transformation of the coordinates into a common coordinate system was carried out for the comparison of the information obtained with the two methods.

In both cases, the post-processing (comparing point clouds to determine the topographic differences between dates) was accomplished using CloudCompare software (GirardeauMonaut et al., 2005, http://www.danielgm.net/cc/), which generates maps of distances between clouds of points corresponding to different survey days.

Measurements were performed at similar intervals between July 2013 and July 2014; in total, four topographic surveys of each study zone were conducted on the following dates: 24 July 2013, 12 November 2013, 26 March 2014 and 24 July 2014.

Rainfall data was recorded in the Araguás catchment (see Nadal-Romero and Reguiés, 2010) and the volume and characteristics of rainfall during the study periods was also analysed.

\section{Results}

Data analyses are conducted on different temporal scales (i) survey/monitoring intervals, and (ii) at annual scale in

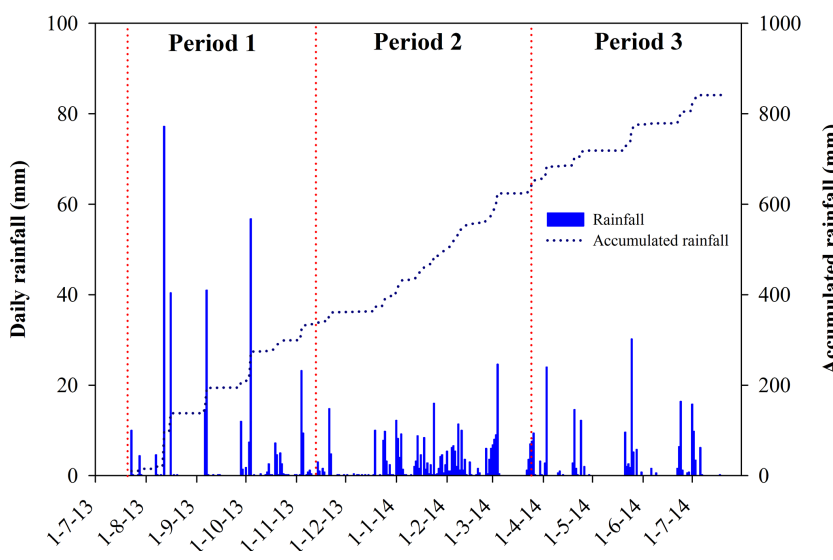

Figure 4. Daily rainfall and accumulated rainfall during the survey period (July 2013-July 2014).

both slopes (north- and south-facing slopes) - using both TLS and SfM photogrammetry. Monitoring intervals and rainfall data are presented in Table 1 and Fig. 4. The length of the monitoring intervals ranged from 112 to 134 days. Maximum daily rainfall was from 24.6 to $77.2 \mathrm{~mm}$, and the maximum $5 \mathrm{~min}$ rainfall intensity ranged from 14.4 to $148.8 \mathrm{~mm} \mathrm{~h}^{-1}$.

The results are structured in three sections. First, the results obtained on the north-facing slopes are analysed (Sect. 3.1) and then the results obtained on the south-facing slope are examined (Sect. 3.2). In both sections, spatial and temporal variability of topographic changes are described. Finally (Sect. 3.3), a comparison between both data analysis and methodologies is carried out.

\subsection{North-facing slopes}

Observed topographic changes over different monitoring survey intervals on the north-facing slope are presented in Figs. 5 and 6 (TLS and SfM photogrammetry data, respectively). Erosion and deposition values are summarized in Table 2. Negative values reflect erosion processes. On the other hand, positive values may reflect deposition processes; however, swelling processes can also influence these values (Vericat et al., 2014).

On north-facing slopes, period 2 (longest period, winter period) showed the strongest and most variable topographic changes (Figs. 5 and 6 ): -0.046 and $-0.051 \mathrm{~m}$ with TLS and SfM photogrammetry, respectively. Most sections of the slope showed signs of rill development.

However, the biggest absolute differences were observed during period 1 (summer). It was the rainiest period $(334.8 \mathrm{~mm})$ due to convective storms with high rainfall intensities $\left(148.8 \mathrm{~mm} \mathrm{~h}^{-1}\right.$; see Table 1$)$. During this period the maximum negative difference $(-0.610$ and $-0.43 \mathrm{~m}$ with TLS and SfM photogrammetry, respectively) was registered due to small movements in the upper part of the slope. A 
Table 1. Summary of time intervals and rainfall data recorded during the monitoring periods.

\begin{tabular}{llrrrr}
\hline & $\begin{array}{l}\text { Monitoring } \\
\text { interval }\end{array}$ & $\begin{array}{r}\text { Number } \\
\text { of days }\end{array}$ & $\begin{array}{r}\text { Total } \\
\text { rainfall (mm) }\end{array}$ & $\begin{array}{r}\text { Max. daily } \\
\text { rainfall (mm) }\end{array}$ & $\begin{array}{r}\text { Max. rainfall 5 min } \\
\text { intensity }\left(\mathrm{mm} \mathrm{h}^{-1}\right)\end{array}$ \\
\hline Period 1 & 23 Jul-12 Nov 2013 & 112 & 334.8 & 77.2 & 148.8 \\
Period 2 & 12 Nov 2013-26 Mar 2014 & 134 & 308.8 & 24.6 & 14.4 \\
Period 3 & 26 Mar-23 Jul 2014 & 119 & 198 & 30.2 & 33.6 \\
Annual period & 23 Jul 2013-23 July 2014 & 365 & 841.6 & 77.2 & 148.8 \\
\hline
\end{tabular}

Table 2. Mean differences, standard deviation and maximum differences (Max. + , deposition; Max. - , erosion) of point clouds obtained for different survey periods with TLS and photogrammetry on north-facing slopes. Bold numbers indicate annual values.

\begin{tabular}{llcccc}
\hline \multicolumn{2}{c}{ North-facing slope } & Period 1 & Period 2 & Period 3 & July 2013-July 2014 \\
\hline \multirow{2}{*}{ TLS } & Mean \pm SD (m) & $-0.020 \pm 0.032$ & $-0.046 \pm 0.050$ & $-0.012 \pm 0.027$ & $-\mathbf{0 . 0 7 7} \pm \mathbf{0 . 0 4 9}$ \\
& Max. $+(\mathrm{m})$ & 0.31 & 0.25 & 0.14 & $\mathbf{0 . 2 5}$ \\
& Max. $-(\mathrm{m})$ & -0.61 & -0.39 & -0.28 & $-\mathbf{0 . 5 9}$ \\
\hline \multirow{2}{*}{ Photogrammetry } & Mean \pm SD (m) & $-0.035 \pm 0.044$ & $-0.051 \pm 0.042$ & $-0.003 \pm 0.025$ & $\mathbf{- 0 . 0 1 7} \pm \mathbf{0 . 0 3 8}$ \\
& Max. $+(\mathrm{m})$ & 0.41 & 0.16 & 0.21 & $\mathbf{0 . 3 4}$ \\
& Max. $-(\mathrm{m})$ & -0.43 & -0.39 & -0.25 & $\mathbf{- 0 . 4 6}$ \\
\hline
\end{tabular}
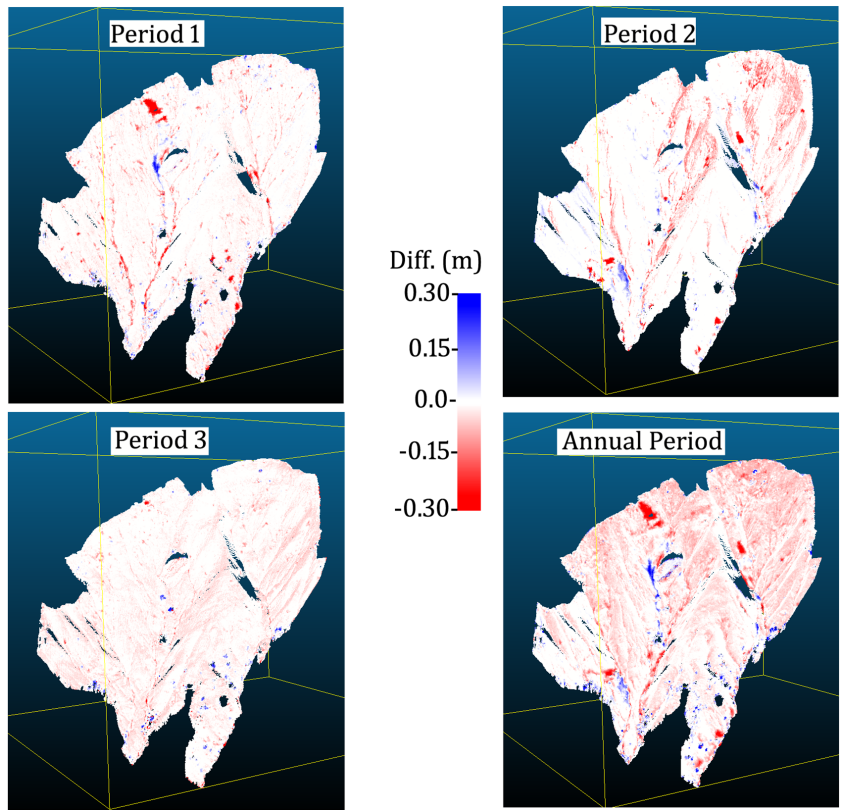

Figure 5. Topographic changes observed at the monitoring intervals and at annual scale obtained with TLS on north-facing slopes (CloudCompare software).

small zone of regolith deposits was also evident just downhill of this movement (period 1; Figs. 5, 6). Period 3 (spring) showed the lowest values, which is consistent with the low rainfall $(198 \mathrm{~mm})$.
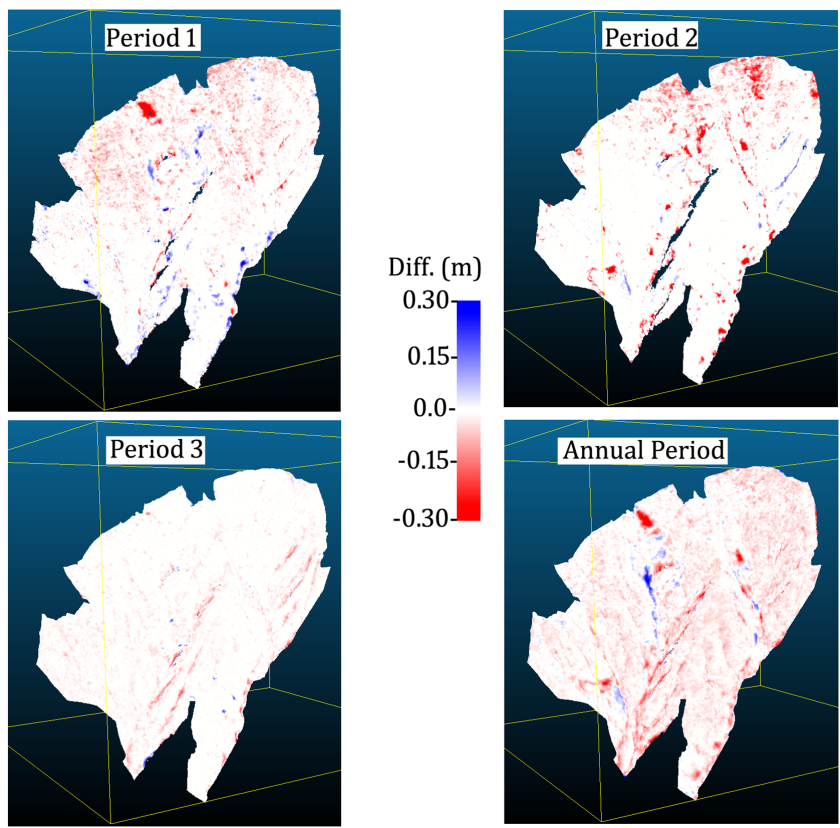

Figure 6. Topographic changes observed at the monitoring intervals and at annual scale obtained with SfM on north-facing slopes (CloudCompare software).

\subsection{South-facing slopes}

On south-facing slopes, period 2 showed the biggest and most variable topographic changes (Figs. 7, 8; Table 3): -0.037 and $-0.001 \mathrm{~m}$ (note the high standard deviation compared to the average difference in Table 1) with TLS and SfM photogrammetry, respectively. An important movement was 
Table 3. Mean differences, standard deviation and maximum differences (Max. + , deposition; Max. - , erosion) of point clouds obtained for different survey periods with TLS and photogrammetry on south-facing slopes. Bold numbers indicate annual values.

\begin{tabular}{llcccc}
\hline \multicolumn{1}{c}{ South-facing slope } & Period 1 & Period 2 & Period 3 & July 2013-July 2014 \\
\hline \multirow{2}{*}{ TLS } & Mean \pm SD (m) & $-0.006 \pm 0.026$ & $-0.037 \pm 0.066$ & $0.011 \pm 0.027$ & $-\mathbf{0 . 0 3 2} \pm \mathbf{0 . 0 7 1}$ \\
& Max. $+(\mathrm{m})$ & 0.179 & 0.52 & 0.24 & $\mathbf{0 . 4 2}$ \\
& Max. $-(\mathrm{m})$ & -0.194 & 0.416 & -0.176 & $\mathbf{0 . 4 5}$ \\
\hline \multirow{2}{*}{ Photogrammetry } & Mean \pm SD (m) & $-0.010 \pm 0.025$ & $0.001 \pm 0.055$ & $0.011 \pm 0.0211$ & $\mathbf{- 0 . 0 0 2} \pm \mathbf{0 . 0 5 6}$ \\
& Max. $+(\mathrm{m})$ & 0.18 & 0.48 & 0.22 & $\mathbf{0 . 4 8}$ \\
& Max. $-(\mathrm{m})$ & -0.22 & -0.42 & -0.17 & $\mathbf{- 0 . 4 2}$ \\
\hline
\end{tabular}
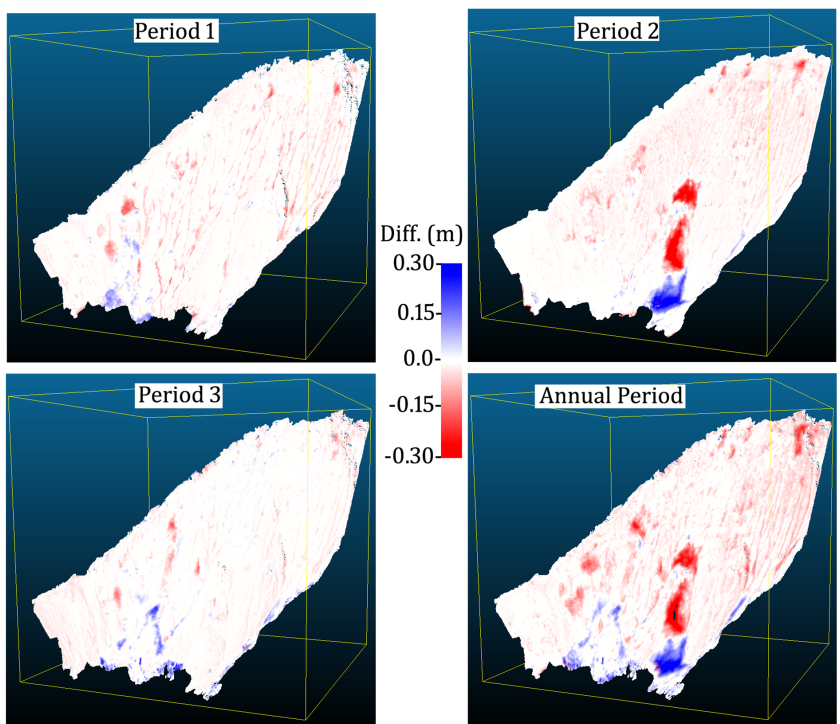

Figure 7. Topographic changes observed at the monitoring intervals and at annual scale obtained with TLS on south-facing slopes (CloudCompare software).

recorded on the lower part of the slope, showing high positive and negative values (both erosion and deposition).

The changes in periods 1 and 3 were smaller, although important rill development was observed in both periods. Small movements and deposition processes at footslopes were recorded (see Figs. 7 and 8).

On the south-facing slope the biggest absolute differences were also observed during period 2, due to the important movement recorded at the lower part of the slope. The maximum negative difference was around $-0.42 \mathrm{~m}$, while the maximum positive difference was around $0.50 \mathrm{~m}$.

\subsection{Joint analysis}

The magnitude of the annual erosion rates was higher on the north-facing slope than on the south-facing slope, -0.077 and $-0.032 \mathrm{~m}$, respectively, recorded using TLS point clouds (see Tables 2 and 3). SfM photogrammetry yielded more moderate differences: -0.017 and $-0.002 \mathrm{~m}$ on the north-
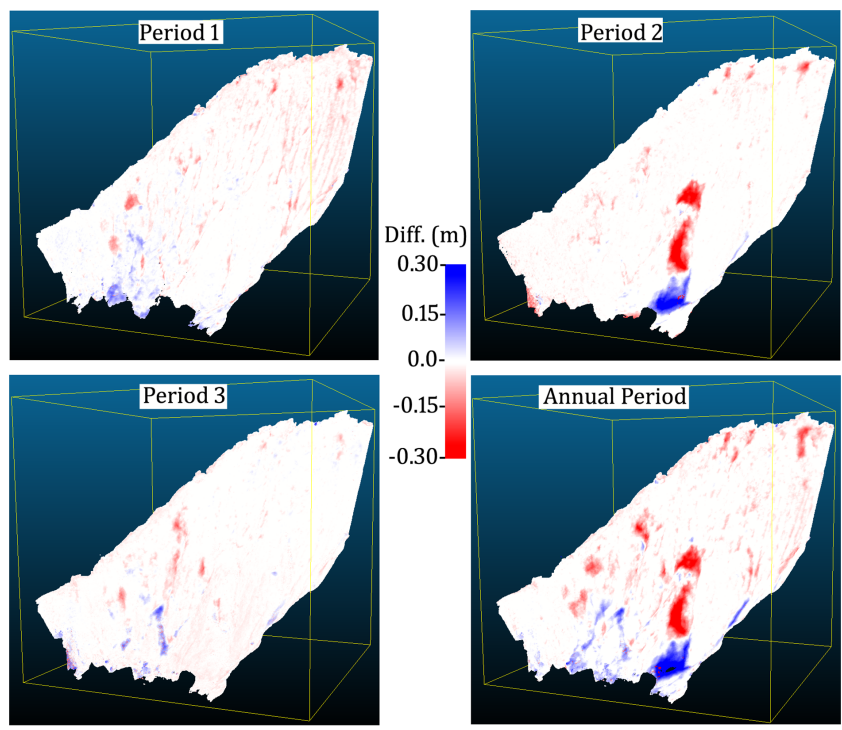

Figure 8. Topographic changes observed at the monitoring intervals and at annual scale obtained with SfM on south-facing slopes (CloudCompare software).

facing and south-facing slopes, respectively. Furthermore, on the south-facing slope the annual maximum negative and positive values are very similar $(0.416$ and $-0.453 \mathrm{~m}$ with TLS, and 0.48 and $-0.42 \mathrm{~m}$ with SfM photogrammetry); however, important differences were observed between the negative and positive absolute maximum values on northfacing slopes $(0.250$ and $-0.590 \mathrm{~m}$ with TLS, and 0.34 and $-0.46 \mathrm{~m}$ with SfM photogrammetry).

In both cases, the variability of topographic changes was very high, as indicated by the high standard deviations (which was even higher at the south-facing slope).

If differences between both methods are analysed, we have to highlight that in south-facing slopes (short distance and small area) the values using both methodologies are really similar; however, on the north-facing slope (long distance and large area) the measurement differences between the two methodologies are remarkable.

Figures 9 and 10 showed a direct comparison of DEMs between techniques considering lidar (TLS) as the reference. 

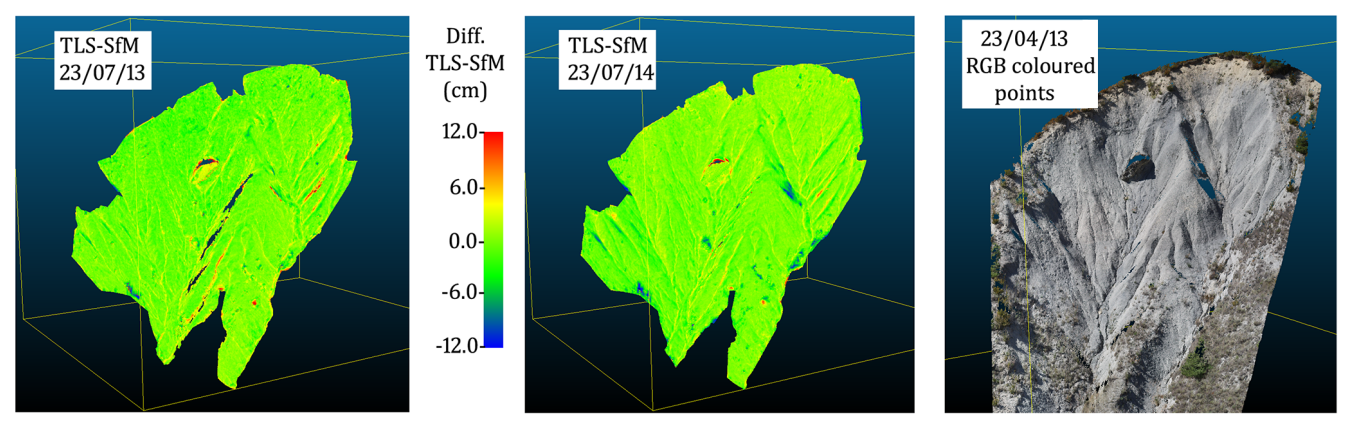

Figure 9. Comparison of DEMs between techniques, considering TLS as the reference, on north-facing slopes. Differences have been calculated for the first and last acquisition dates (23 July 2013 and 23 July 2014) (cloud compare software). A RGB coloured points image is added in the right panel as an overview of the north-facing slopes
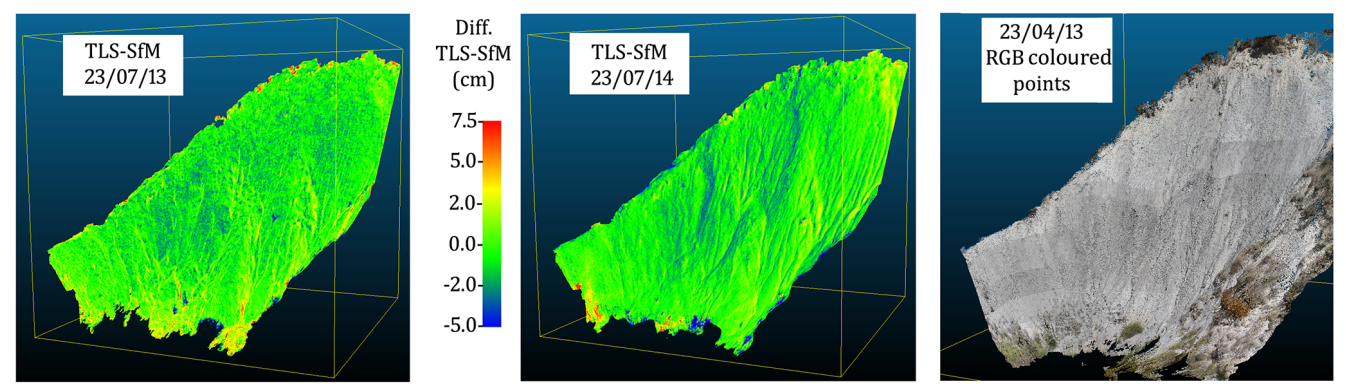

Figure 10. Comparison of DEMs between techniques, considering TLS as the reference, on south-facing slopes. Differences have been calculated for the first and last acquisition dates (23 July 2013 and 23 July 2014) (cloud compare software). A RGB coloured points image is added in the right panel as an overview of the south-facing slopes

Differences have been calculated for the first and last acquisition dates (23 July 2013 and 23 July 14). Big differences occurred in small areas, where small vegetation patches were present (almost all vegetation was eliminated from the point clouds, but some influence can be appreciated in the exterior limits of the selected slopes). Small differences were observed in "deep" concavities (yellow colours in the comparison figures), because in these areas the SfM was not able to accurately reproduce a precise topography. Other errors were usually located in ridges and the areas behind them, from the TLS perspective, showing one of the main TLS limitations: with only one point of view, some areas are hidden. Average differences (Table 4) were higher in north-facing slopes (also the highest standard deviations were recorded in this slope) in both surveys because of the increase on distance of data acquisition and the presence of shadows.

\section{Discussion}

\subsection{Geomorphological dynamics}

Both techniques can produce high-resolution topographic models with centimetre accuracy. By comparing different point clouds of the same area, obtained at different time peri- ods, we analysed variations in the topographic characteristics of the terrain and the temporal geomorphological dynamics.

First, it must be highlighted that the variability of the recorded topographic changes was very high, as reflected by the high standard deviation (see Tables 2 and 3). The detailed analysis of the point clouds showed the geomorphological dynamics of these severely eroded areas. The results indicated that the geomorphological dynamics on north-facing slopes were more intense than on south-facing slopes, except for punctual high variations on the south face. Various studies have highlighted terrain aspect as an important factor in the geomorphological development of badlands (e.g. CalvoCases and Harvey, 1996; Descroix and Olivry, 2002; Pulice et al., 2013).

The values presented in Tables 2 and 3 also showed that the highest topographic changes were recorded during winter periods. Also, other studies highlighted that the development and weathering dynamics of regolith in north-facing slopes are more active in winter, due to the freeze-thaw weathering processes, while south-facing slopes are dominated by the development of crusts associated with wetting-drying processes (Nadal-Romero et al., 2007; Nadal-Romero and Reguiés, 2010). It has to be noted that shrinking-swelling and freeze-thaw processes may cause dilation of surface mate- 
Table 4. Mean differences and standard deviation of point clouds obtained with both methods calculated for the first and last acquisition dates (23 July 2013 and 23 July 2014).

\begin{tabular}{lll}
\hline & 24 July 2013 & 24 July 2014 \\
\hline North-facing slopes (TLS-SfM) (m) & $-0.013 \pm 0.0308$ & $-0.0201 \pm 0.0326$ \\
\hline South- facing slopes (TLS-SfM) (m) & $-0.002 \pm 0.0202$ & $-0.006 \pm 0.0141$ \\
\hline
\end{tabular}

rial, which results in a net surface elevation; however, this study did not take these small variations into account.

North-facing slopes experienced small mud or debris flows, although also south-facing slopes had these flows due to the high slope gradient (Figs. 9, 10), showing the importance of climate and topographic factors in badlands development. These types of movements have also been recorded in humid badlands in southeast France using a small portable camera in the Draix catchment (miniature debris flows MDF) (Yamakoshi et al., 2009). Nadal-Romero et al. (2007), based on field evidence and laboratory work, suggested that in these badland morphologies shallow landslides and small mudflows commonly occur during prolonged rainfall events. These erosion processes produced the development of fans at the base of slopes and near the main channels, processes also observed in different badland morphologies (Balasch, 1998; Regüés and Gallart, 2004; Desir and Marín, 2007). It is also remarkable that during summer, convective storms of high intensity and short duration overcome infiltration capacity and generate intense concentrated runoff. Rill and gully development usually appear during these events and are significant in sediment production (Nadal-Romero and Regüés, 2010). Both TLS and SfM photogrammetry captured these processes, which confirms that both are good techniques for studying geomorphological processes in badland areas.

TLS results on the north-facing slope indicated a negative difference of $77 \mathrm{~mm} \mathrm{yr}^{-1}$, while on the south-facing slope the negative values are lower, $32 \mathrm{~mm} \mathrm{yr}^{-1}$. More moderate differences are recorded using SfM photogrammetry point clouds with annual values of 17 and $2 \mathrm{~mm} \mathrm{yr}^{-1}$ on the north-facing and south-facing slopes, respectively. Nevertheless, these values should be contextualized with the observed standard deviation of $38 \mathrm{~mm}$ for north-facing and $56 \mathrm{~mm}$ for south-facing slopes. Nadal-Romero et al. (2008) estimated erosion rates (represented as a lowering of the soil surface) determined from the suspended sediment loss measured at the outlet of the catchment (converted to centimetres) and taking into account the specific weight of the marl $\left(2.75 \mathrm{~g} \mathrm{~cm}^{-3}\right.$ ). During the study period (November 2005January 2007), March and September 2006 were particularly active in terms of sediment transport, with recorded drops in soil surface of 13 and $8 \mathrm{~mm}$, respectively. The estimate of annual erosion rates for the entire catchment was $27.5 \mathrm{~mm} \mathrm{yr}^{-1}$. High erosion rates, similar to the ones obtained in this study, were recorded in different badland areas. Using similar methodology, Vericat et al. (2014) mea- sured an annual change of around $-60 \mathrm{~mm} \mathrm{yr}^{-1}$ in the eastern Pyrenees (Spain). Lower values were registered in subhumid badland areas of southern Tuscany $\left(15-20 \mathrm{~mm} \mathrm{yr}^{-1}\right.$ ) (Cicacci et al., 2008) and the Prealp catchments in France (over $30 \mathrm{~mm} \mathrm{yr}^{-1}$ ) (Chodzko et al., 1991) using invasive traditional methodologies.

\subsection{New non-invasive tools}

This study demonstrates that both methodologies adequately facilitate subsequent analysis - both in a quantitative (metric) and qualitative (interpretive) way. Both offer a good opportunity to safely measure landform without soil disturbance, with high spatial resolution and in a relative short time period. Table 5 presents the advantages and disadvantages of both methods.

Both methods allow for fast and automatic image processing. Nevertheless, SfM photogrammetry reduces the data collection effort in the field, although post-processing is still labour-intensive. TLS is an expensive (and quite heavy) tool, while SfM photogrammetry is relatively cheap and easy to use. Castillo et al. (2012) calculated the cost of TLS at 10 times the cost of 3-D photogrammetry.

The comparison between both methods (Figs. 9, 10; Table 4) showed that results were similar in both cases, although significant differences can be observed in small points, especially in the presence of shadows and vegetation.

Our study demonstrated that SfM delivers good accuracy and is really useful for field application in geomorphological and soil erosion studies for observing changes at the centimetre scale (depending on the working distance). In our case, the quality of the images should be improved in order to obtain better accuracy, paying special attention to illumination changes during the acquisition of the images, which have been observed as an important error-causing interference. The number of pictures could be a problem to be solved together with the computer memory (a large memory is needed to process a large number of high-quality pictures). Nevertheless, if the image acquisition locations are well established and the image overlapping is done well, the number of needed images is not very high (5-10 pictures). Micheletti et al. (2015) carried out an analysis in similar areas and at the same scale and obtained good and valid models with 13 images.

TLS shows better performance in differentiating small displacement of terrain (resolution of surface models) (e.g. rill 
Table 5. Advantages and disadvantages of TLS and photogrammetry methodologies for studying geomorphological processes in badland areas.

\begin{tabular}{lll}
\hline & Advantage & Disadvantage \\
\hline TLS & - non-invasive & - high economic cost \\
& - pinpoint accuracy & - heavy material (difficulties for portability) \\
& - high-accuracy potential and automation level & - longer measurement time \\
& - high data acquisition & - problems with little misalignments of reference points \\
& post-processing is fast & - sight shadowing \\
& & \\
\hline Photogrammetry & - non-invasive & - centimetric accuracy \\
& - low costs & - worse adaptation to survey large areas \\
& - small format: low weight & - post-processing is still labour-intensive \\
& - reduce data collection time by $\sim 80 \%$ & - problems with illumination changes \\
& - high number of photos to minimize missing areas & \\
\hline
\end{tabular}

development). However, due to time restrictions we have worked with a single scan position, causing the shadowing effect of terrain (the so-called sight shadowing), which does not allow retrieving data from different areas of the site and therefore missing information. This missing information due to terrain curvature observed in some areas with the TLS (north slope) is avoided with SfM photogrammetry because different points of view of the study area were easily acquired (see differences in Figs. 9 and 10). Nevertheless, in the presented analyses and annual erosion rates these shadow areas have been removed in SfM photogrammetry to consider exactly the same area with both methods.

SfM photogrammetry performs better for the spatial distribution of the point cloud; for areas closer to the TLS the point resolution increases, while for longer distances it decreases, which is one of the main limitations of this technology. However, TLS does provide a higher resolution of surface models. Indeed, the high number of points obtained for short distances to the TLS in comparison to those obtained for large distances is one limitation for these devices. This has encouraged minimizing scan distances when possible (Heritage and Hetherington, 2007). On the contrary, the SfM technique does not show this high dependence on distance due to the multiple points of view of the surveyed area (Smith and Vericat, 2015). This is one of the main advantages when compared to TLS.

TLS and SfM photogrammetry data sets supported quantifiable data that previously had to be gathered through very labour- and time-intensive field measurements. Castillo et al. (2012) compared the accuracy, time and cost of the conventional and new techniques. They observed that SfM photogrammetry is the method that produces the best approximation to the TLS. They also suggested that traditional methods (2-D methods) can produce significant volume errors. Marzolff and Poesen (2009) suggested that compared to remote-sensing imagery, field methods have the disadvantage of time-consuming measurements and, thus, usually cover- ing rather small areas with a limited sampling density. Perroy et al. (2010) concluded that old methods (traditional and invasive) are time-consuming, tedious, labour intensive and sometimes more expensive.

\subsection{Future research}

Further research needs to focus on analysing geomorphological processes (erosion and deposition) and their controlling topographic (slope, aspect, roughness) and meteorological factors (rainfall and temperature) over a number of eventscale monitoring periods. With the new surveys, a higher number of pictures will be taken and TLS surveys will be taken from two points. With this information we will check some of the observed limitations of both methodologies. The next stages of the project will focus also on the analysis and comparison of TLS and SfM photogrammetry data with data obtained with a new turbidimeter installed in the catchment at the beginning of 2015 .

\section{Conclusions}

The study applied and compared the performance of the terrestrial laser scanner and the photogrammetric techniques in investigating the geomorphological dynamics and topographic changes on two active slopes in humid badland areas. TLS and SfM photogrammetry (non-intrusive methods) show high precision and obtain high-resolution topographic information. We used the combination of TLS and SfM photogrammetry to maximize their advantages while minimizing the disadvantages of each technique.

The results show that TLS and SfM photogrammetry data sets provide opportunities in the study of topographic change of very erosion-prone landscapes (e.g. badlands) where the use of conventional, invasive topographic technologies is limited. SfM photogrammetry is a powerful and low-cost tool for evaluating the rate and spatiotemporal development of denudation processes at short distances and small areas. 
Small problems should be solved using a camera with higher resolution or a higher number of pictures. We consider that SfM photogrammetry can be a good tool in geomorphological studies when carried out by taking pictures at short distances.

The data recorded in the course of a year at different seasonal intervals demonstrated that north-facing slopes experienced more intense and faster geomorphological dynamics than south-facing slopes. Different seasonal processes were observed: the biggest topographic differences coincided with the winter periods and the high-intensity-rainfall incidents in summer.

Acknowledgements. Support for this research was provided by the projects HIDROCAES (CGL2011-27574-C02-01) and INDICA (CGL2011-27753-C02-01) funded by the Spanish Ministry of Economy and Competition. E. Nadal-Romero was the recipient of a Marie Curie IEF grant (Seventh EU Framework Programme project MED-AFFOREST PIEF-GA-2013-624974). J. Revuelto was the recipient of a FPU grant (Spanish Ministry).

Edited by: J. A. Gomez

\section{References}

Alexander, R. W.: Difference between "calanchi" and "biancane" badlands in Italy, in: Badland Geomorphology and Piping, edited by: Bryan, R. and Yair, A., Geobooks, Norwich, 71-88, 1982.

Balasch, J. C.: Resposta hidrològica i sedimentària d'una petita conca de muntanya analitzades at diferent escala temporal, $\mathrm{PhD}$ thesis, Universitat de Barcelona, 376 pp., 1998.

Ballesteros-Cánovas, J. A., Bodoque, J. M., Lucía, A., MartínDuque, J. F., Díez-Herrero, A., Ruiz-Villanueva, V., Rubiales, J. M., and Genova, M.: Dendrogeomorphology in badlands: Methods, case studies and prospects, Catena, 106, 113-122, 2013.

Baltsavias, E. P.: A comparison between photogrammetry and laser scanning, ISPRS-J. Photogramm. Remote Sens., 54, 83-94, 1999.

Barnhart, T. B. and Crosby, B. T.: Comparing two methods of surface change detection on an evolving thermo karst using hightemporal-frequency Terrestrial Laser Scanning, Selawik River, Alaska, Remote Sens., 5, 2813-2837, 2013.

Bitelli, G., Dubbini, M., and Zanutta, A.: Terrestrial Laser Scanning and Digital Photogrammetry techniques to monitor landslide bodies, in: XXth ISPRS Congress: Proceedings of Commission V, Istanbul, Turkey, 246-251, 2004.

Bryan, R. and Yair, A. (Eds.): Perspectives on studies of badland geomorphology, in: Badland Geomorphology and Piping, Geobooks, Norwich, 1-12, 1982.

Calvo-Cases, A. and Harvey, A. M.: Morphology and development of selected badlands in southeast Spain: Implications of climatic change, Earth Surf. Process. Landf., 21, 725-735, 1996.

Cantón, Y., Domingo, F., Solé-Benet, A., and Puigdefábregas, F.: Hydrological and erosion response of a badlands system in semiarid SE Spain, J. Hydrol., 252, 65-84, 2001.

Cardenal Escarnena, J., Mata de Castro, E., Pérez García, J.L., Mozas Calvache, A., Fernández del Castillo, T., Delgado Gar- cía, J., Ureña Cámara, M., and Castillo, J. C.: Integration of photogrammetric and terrestrial laser scanning techniques for heritage documentation, Virtual Archaeology Review, 2, 53-57, 2011.

Castillo, C., Pérez, R., James, M. R., Quinton, J. N., Taguas, E. V., and Gómez, J. A.: Comparing the Accuracy of Several Field Methods for Measuring Gully Erosion, Soil Sci. Soc. Am. J., 76, 1319-1332, 2012.

Castillo, C., James, M. R., Redel-Macías, M. D., Pérez, R., and Gómez, J. A.: The SF3M approach to 3-D photo-reconstruction for non-expert users: application to a gully network, SOIL Discuss., 2, 371-399, doi:10.5194/soild-2-371-2015, 2015.

Chodzko, J., Lecompte, M., Lhénaff, R., and Marre, A.: Vitesse de l'érosion dans les roubines des Baronnies (Drôme), Physio-Géo, 22-23, 21-28, 1991.

Ciccacci, S., Galiano, M., Roma, M. A., and Salvatore, M. C.: Morphological analysis and erosion rate evaluation in badlands of Radicofani area (southern Tuscany - Italy), Catena, 74, 87-97, 2008.

Creus, J.: El clima del Alto Aragón Occidental. Monografías del Instituto de Estudios Pirenaicos 109, Consejo Superior de Investigaciones Científicas, Jaca, 1983.

Descroix, L. and Olivry, J. C.: Spatial and temporal factors of erosion by water of black marls in the badlands of the French Southern Alps, Hydrol. Sci. J., 47, 227-242, 2002.

Desir, G. and Marín, C.: Factors controlling the erosion rates in a semi-arid zone (Bardenas Reales, NE Spain), Catena, 71, 31-40, 2007.

Fairbridge, R. W.: Encyclopedia of geomorphology, Stroudsburg, PA, Dowden, Hutchinson and Ross, 1968.

Fonstad, M. A., Dietrich, J., Courville, B. C., Jensen, J., and Carbonneau, E.: Topographic structure from motion: a new development in photogrammetric measurement, Earth Surf. Process. Landf., 38, 421-430, 2013.

Gallart, F., Marignani, M., Pérez-Gallego, N., Santi, E., and Maccherini, S.: Thirty years of studies on badlands, from physical to vegetational approaches, A succinct review, Catena, 106, 4-11, 2013.

Gallart, F., Pérez-Gallego, N., Latron, J., Catari, G., MartínezCarreras, N., and Nord, G.: Short- and long-term studies of sediment dynamics in a small humid mountain Mediterranean basin with badlands, Geomorphology, 196, 242-251, 2013.

García-Ruiz, J. M., Beguería, S., Nadal-Romero, E., GonzálezHidalgo, J. C., Lana-Renault, N., and Sanjuán, Y.: A metaanalysis of soil erosion rates across the world, Geomorphology, 239, 160-173, 2015.

Girardeau-Montaut, D., Roux, R. M., and Thibault, G.: Change detection on points cloud data acquired with a ground laser scanner, in: Workshop Laser Scanning 2005, ISPRS, Enschede, the Netherlands, 6 pp., 2005.

Gómez-Gutiérrez, A., Schnabel, S., Berenguer-Sempere, F., Lavado-Contador, F., and Rubio-Delgado, J.: Using 3-D photoreconstruction methods to estimate gully headcut erosion, Catena, 120, 91-101, 2014.

Grauso, S., Pagano, A., Fattoruso, G., De Bonis, P., Onori, F., Regina P., and Tebano, C.: Relations between climaticgeomorphological parameters and sediment yield in a Mediterranean semi-arid area (Sicily, southern Italy), Environ. Geol., 54, 219-234, 2008. 
Heritage, G. and Hetherington, D.: Towards a protocol for laser scanning in fluvial geomorphology, Earth Surf. Process. Landf. 32, 66-74, 2007.

Howard, A. D.: Badlands, in: Geomorphology of desert environments, edited by: Abrahams, A. D. and Parsons, A. J., Chapman and Hall, London, 213-242, 1994.

Kaiser, A., Neugirg, F., Rock, G., Mueller, C., Haas, F., Ries, J., and Schmidt, J.: Small- Scale Surface Reconstruction and Volume Calculation of Soil Erosion in Complex Moroccan Gully Morphology Using Structure from Motion, Remote Sens., 6, 70507080, 2014.

Lam, K.: Patterns and rates of slope wash on the badlands of Hong Kong. Earth Surf. Process. Landf., 2, 319-332, 1977.

López-Saez, J., Corona, C., Stoffel, M., Rovéra, G., Astrade, L., and Berger, F.: Mapping of erosion rates in marly badlands based on a coupling of anatomical changes in exposed roots with slope maps derived from LiDAR data, Earth Surf. Process. Landf., 36, 1162-1171, 2011.

Lucía, A., Martín-Duque, J. F., Benjamin Laronne, J., and SanzSantos, M. A.: Geomorphic dynamics of gullies developed in Sandy slopes of Central Spain, Landform Analysis, 17, 91-97, 2011.

Martínez, S., Ortiz, J., and Gil, M. L.: Geometric documentation of historical pavements using automated digital photogrammetry and high-density reconstruction algorithms, J. Archael. Sci., 53, 1-11, 2015.

Martínez-Casasnovas, J. A. and Ramos, M. C.: Erosión por cárcavas y barrancos en el área de viña del Alt Penedés-Anoia (NE España), Cuadernos de Investigación Geográfica, 35, 223-238, 2009.

Martínez-Murillo, J. F., Nadal-Romero, E., Regüés, D., Cerdà, A., and Poesen, J.: Soil erosion and hydrology of the western Mediterranean badlands throughout rainfall simulation experiments: A review, Catena, 106, 101-112, 2013.

Marzolff, I. and Poesen, J.: The potential of 3D gully monitoring with GIS using high-resolution aerial photography and a digital photogrammetry system, Geomorphology, 111, 48-60, 2009.

Mathys, N., Brochot, S., Meunier, M., and Richard, D.: Erosion quantification in the small marly experimental catchments of Draix (Alpes de Haute Provence, France), Calibration of the ETC rainfall-runoff-erosion model, Catena, 50, 527-548, 2003.

Michetti, N., Chandler, J. H., and Lane, S. N.: Investigating the geomorphological potential of freely available and accessible structure-from-motion photogrammetry using a smartphone, Earth Surf. Process. Landf., 40, 473-486, 2015.

Nadal-Romero, E. and Regüés, D.: Geomorphological dynamics of subhumid mountain badland areas - weathering, hydrological and suspended sediment transport processes: a case study in the Araguás catchment (Central Pyrenees) and implications for altered hydroclimatic regimes, Prog. Phys. Geogr., 34, 123-150, 2010.

Nadal-Romero, E., Regüés, D., Martí-Bono, C., and Serrano, P.: Badland dynamics in the Central Pyrenees: temporal and spatial patterns of weathering processes, Earth Surf. Process. Landf., 32, 888-904, 2007.

Nadal-Romero, E., Latron, J., Martí-Bono, C., and Regüés, D.: Temporal distribution of suspended sediment transport in a humid Mediterranean badland area: the Araguás catchment, Central Pyrenees, Geomorphology, 97, 601-616, 2008.
Nadal-Romero, E., Martínez-Murillo, J. F., Vanmaercke, M., and Poesen, J.: Scale-dependency of sediment yield from badland areas in Mediterranean environments, Prog. Phys. Geogr., 35, 297332, 2011.

Nadal-Romero, E., Martínez-Murillo, J. F., Vanmaercke, M., and Poesen, J.: Corrigendum to Scale-dependency of sediment yield from badland areas in Mediterranean environments" (Progress in Physical Geography 35 (3) (2011), 297-332), Prog. Phys. Geogr., 38, 381-386, 2014.

Nadel, D., Filim S., Rosenberg, D., and Miller, V.: Prehistoric bedrock features: Recent advances in 3D characterization and geometrical analyses, J. Archaeol. Sci., 53, 331-344, 2015.

Perroy, R. L., Bookhagen, B., Asner, G., and Chadwick, O. A.: Comparison of gulyy erosion estimates using airborne and ground-based LiDAR on Santa Cruz Island, California, Geomorphology, 118, 288-300, 2010.

Prokop, A.: Assessing the applicability of terrestrial laser scanning for spatial snow depth measurements, Cold Regions Sci. Technol., 54, 155-163, 2008.

Pulice, I., Di Leob, P., Robustellia, G., Scarcigliaa, F., Cavalcanteb, F., and Belvisob, C.: Control of climate and local topography on dynamic evolution of badland from southern Italy (Calabria), Catena, 109, 83-95, 2013.

Regüés, D. and Gallart, F.: Seasonal patterns of runoff and erosion responses to simulated rainfall in a badland area in Mediterranean mountain conditions (Vallcebre, Southeastern Pyrenees), Earth Surf. Process. Landf., 29, 755-67, 2004.

Revuelto, J., López-Moreno, J. I., Azorin-Molina, C., Zabalza, J., Arguedas, G., and Vicente-Serrano, S. M.: Mapping the annual evolution of snow depth in a small catchment in the Pyrenees using the long-range terrestrial laser scanning, J. Maps, 0, 1-15, 2014.

Sadiki, A., Faleh, A., Navas, A., and Bouhlassa, S.: Assessing soil erosion and control factors by the radiometric technique in the Boussouab catchment, Eastern Rif, Morocco, Catena, 71, 13-20, 2007.

Saez, J. L., Corona, C., Stoffe, M., Rovéra, G., Astrade, L., and Berger, F.: Mapping of erosion rates in marly badlands based on a coupling of anatomical changes in exposed roots with slope maps derived from LiDAR data, Earth Surf. Process. Landf., 36, 1162-1171, 2011.

Sirvent, J., Desir, G., Gutierrez, M., Sancho, C., and Benito, G.: Erosion rates in badland areas recorded by collectors, erosion pins and profilometer techniques (Ebro Basin, NE-Spain), Geomorphology, 18, 61-75, 1997.

Smith, M. W. and Vericat, D.: From experimental plots to experimental landscapes: topography, erosion and deposition in subhumid badlands from Structure-from-Motion photogrammetry, Earth Surf. Process. Landf., doi:10.1002/esp.3747, 2015.

Vergari, F., Della Seta, M., Del Monte, M., Fredi, P., and Lupia Palmieri, E.: Long- and short-term evolution of several Mediterranean denudation hot spots: The role of rainfall variations and human impact, Geomorphology, 183, 14-27, 2013.

Verhoeven, G., Taelman, D., and Vermeulen, F.: Computer Visionbased orthophoto mapping of complex archaological sites: The ancient quarry of Pitaranha, Archaeometry, 54, 1114-1129, 2012.

Vericat, D., Smith, M. W., and Brasington, J.: Patterns of topographic change in sub-humid badlands determined by high res- 
olution multi-temporal topographic surveys, Catena, 120, 164176, 2014.

Walling, D. E.: Drainage basin studies, in: Field experiments and measurement programs in geomorphology, edited by: Slaymaker, O., Balkema, Rotterdam, 17-60, 1991.

Westoby, M. J., Brasington, J., Glasser, N. F., Hambrey, M. J., and Reynolds, J. M.: "Structure-from-Motion" photogrammetry: A low-cost, effective tool for geoscience application, Geomorphology, 179, 300-314, 2012.
Yamakoshi, T., Mathys, N., and Klotz, S.: Time-lapse video observation of erosion processes on the Black Marls badlands in Southern Alps, France, Earth Surf. Process. Landf., 34, 314-318, 2009. 